\title{
A Design Method of Corrugated Steel Shear Wall under Earthquake Motion
}

\author{
Xiao-Tong PENG ${ }^{1,}$, , Chen LIN ${ }^{2, b}$, Ting-Ting ZHANG ${ }^{1, c}$, Xu ZHANG ${ }^{1, d}$ \\ ${ }^{1}$ School of Civil Engineering and Architecture, University of Jinan, Jinan 250022, China \\ ${ }^{2}$ School of Architecture and Landscape Design, Shandong University of Art \& Design, Jinan 250014, \\ China \\ apengxito@163.com, blinch77@126.com, c1062349003@qq.com,,hpfanss63907@163.com
}

Keywords: corrugated steel shear wall, steel frame, design method, shear bearing capacity, calculation example.

Abstract. As a natural anti-buckling component, corrugated steel shear wall is adopted to increase the lateral stiffness of steel frames. Taking a 6-story office building as an example, a design method for corrugated steel shear wall was produced based on the shear strength design theory of steel members. In which, the layout orientation of the corrugated steel plate, waveform selection, plate thickness, joints and connections strength were considered. The results indicate that the design method is feasible, effective, and have a good connection port with current codes.

\section{Introduction}

Steel plate shear wall(SPSW) is a widely used lateral force resistance system. However, it is prone to buckle out of plane, and its lateral stiffness drops sharply after elastic buckling. Therefore, stiffened steel shear walls and composite steel plate shear walls are produced by Alinia and Shafaei respectively ${ }^{[1-2]}$ to delay the buckling of steel plates, thus, the buckling of SPSW can be restrained to a certain degree. The corrugated steel plate is quailed as shear walls in steel frame for its large initial stiffness and shear yield strength. It can reduce the out-of-plane deformation of shear walls and improve lateral stiffness of steel frames. In 2004, using steel plates as shear walls was firstly proposed by Hossain and Wright ${ }^{[3]}$. The buckling performance of corrugated steel shear walls(CSSWs) was then studied by Li Feng et al ${ }^{[4-5]}$. In 2005 , Berman and Bruneau ${ }^{[6]}$ found that the oblique arrangement of corrugated steel plates had an impact on the hysteretic behavior of CSSWs. The results of Zhu Wei [7] indicated that the shear wall has the best lateral resistant performance when corrugations placed horizontally.

In summary, scholars around the world have studied the buckling performance and arrangement of CSSWs, while few design methods being applied in engineering was proposed. The design method of the traditional SPSW is optimized in this paper, and a set of systematic design method of the CSSWs is proposed.

\section{SCSW design method}

Taking a 6-story office building as a prototype, a steel frame- corrugated steel shear walls was designed (Fig. 1). The height of the model is 3.6 meters and the distance between columns is 6 meters. The surrounding frame structure only bears the vertical load of the office building.

The frame beams and columns are all I-shaped sections and rigid connection is used in the model. To avoid effects of the tension field of steel plates on the frame, both sides of the corrugated steel plates are separated from the columns. The upper and lower edges of the corrugated steel plates are connected to the frame girder by connection plates, and those connection plates are welded to the corrugated steel plate and the frame girder by fillet welds. 


\section{Corrugations and Waveform}

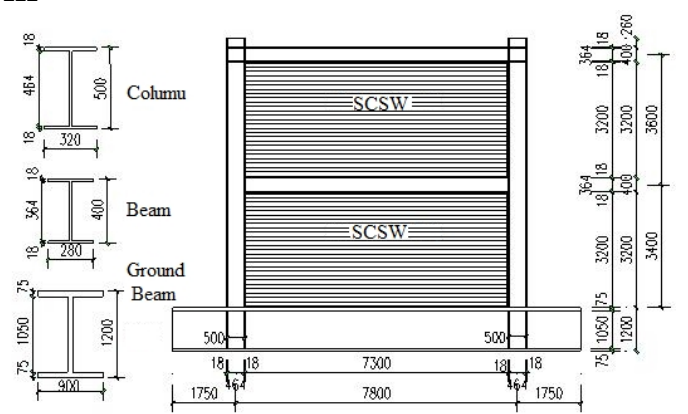

Fig.1 Model of CSSW

The lateral stiffness of corrugated steel sheet is affected by the settle direction of corrugated steel plate. It is known ${ }^{[7]}$ that the corrugated steel plate has the highest lateral stiffness when placed horizontally. Therefore, horizontal placement should be the optimal option in practice.

There are three kinds of waveforms of corrugated steel plate: triangular, sine and trapezoidal. Owing to the acute angle of connection, the triangular waveform generate stress concentration easily. While the sinusoidal waveform avoids stress concentration with highly cost. Therefore, the trapezoid sections selected in this design. According to the experimental researches on the bearing capacity of different waveform of corrugated steel plates ${ }^{[8]}$, the bearing capacity is desirable when wavelength $q$ varies $50 \sim 300 \mathrm{~mm}$, the wave height $d$ varies $30 \sim 100 \mathrm{~mm}$, the length ratio between the horizontal section and the oblique section $a / c$ varies 1 2, the ratio of the developed length of wavelength $S$ and the wavelength $q$ varies $1.1 \sim 1.4$, the angle $\theta$ varies $30^{\circ} \sim 60^{\circ}$. The recommended waveform in

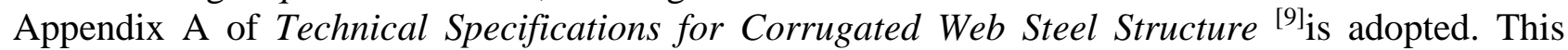
waveform has a high shear yield strength which can prevent the premature shear buckling. A horizontal honeycomb corrugated steel plate was formed by two parallel-connected trapezoidal corrugated steel plates with the specific dimensions (Fig. 2). Its specific size is $a=70 \mathrm{~mm}, b=d=50 \mathrm{~mm}$, $\theta=45^{\circ}, c=70.71 \mathrm{~mm}$.

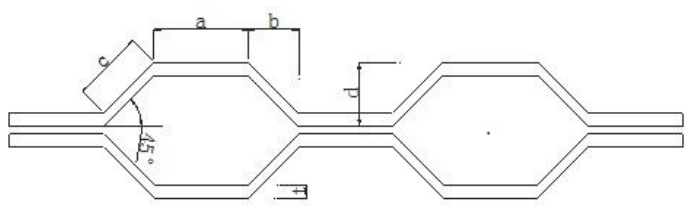

Fig. 2 Corrugated Plate Geometric Parameter

To ensure the sufficient initial stiffness of CSSWs, high-strength steel is used for the edge frame. And low-yielding and high-ductility steel is used for the corrugated steel plate. Therefore, Q345 steel is applied for outer frame and Q235 steel for corrugated steel plates.

\section{Plate Thickness}

The corrugated steel plate thickness is the key point in the design of CSSW's design. The bending inertia moment of plates increases when the plates bent. which equals to the increasing of plate thickness due to the change of the sectional shape. According the shear capacity of corrugated steel plate ${ }^{[10]}$, the shear bearing capacity $(e \cdot \tau \cdot l \cdot t)$ of corrugated steel plate should be bigger than the horizontal seismic force $\left(\gamma_{R} V_{i}\right)$. As follows:

$$
\begin{aligned}
& e \tau l t>\gamma_{R} V_{i} \\
& e=A_{b} / A_{0}=2.34
\end{aligned}
$$

Where,

$A_{b}$--- the section area of the corrugated steel plate per-wavelength (flake shaded area in Fig. 3);

$A_{0}$---the section area of the flat steel plate per-wavelength (diagonal shade area in Fig. 3);

$\tau$---the shear stress of the CSSW, $\tau_{y}=f_{\mathrm{y}} / \sqrt{3}$;

$f_{\mathrm{y}}$---the tensile strength design value of the steel;

$\gamma_{R}$---the seismic partial coefficient, $\gamma_{R}=1.2$;

$V_{i}$--- the i-th floor shear force. 
The formula for minimum thickness of the corrugated steel plate is:

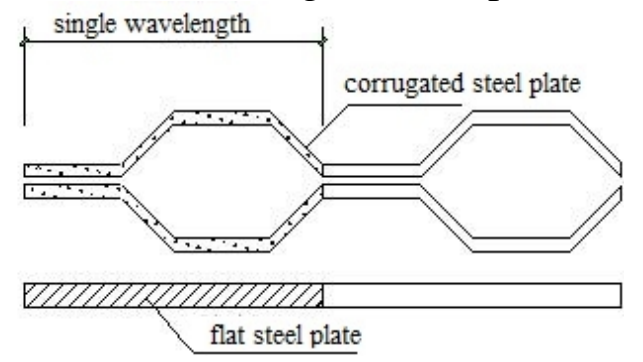

Fig. 3 Bearing Area Ratio(e) Per-wavelength

$t>\sqrt{3} \gamma_{R} V_{i} /\left(e \cdot l \cdot f_{y}\right)$

The formula for buckling strength of CSSWs is:

$$
\begin{aligned}
& \tau_{l}=K_{l} \cdot\left\{\left(\pi^{2} E\right) /\left[12\left(1-v^{2}\right)\right]\right\} \cdot(t / \omega)^{2} \\
& \omega=\max (a, c)
\end{aligned}
$$

Where:

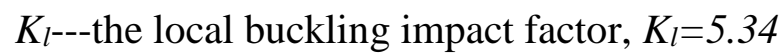

$E$---the elastic modulus, $E=2 \times 10^{5} \mathrm{~N} / \mathrm{mm}^{2}$;

$v$---Poisson's ratio, $v=0.3$

Taking the local buckling of corrugated steel plates as the limit state, the maximum thickness of the corrugated steel plate is decided by the buckling of the corrugated steel plate. The formula for maximum thickness of the corrugated steel plate is:

$$
t<(2 \omega / \pi) \cdot \sqrt{\left\{\left[3 \tau_{y}\left(1-v^{2}\right)\right] /\left(K_{l} E\right)\right\}}
$$

According to equations above, the thickness of the corrugated steel plate can be obtained:

$$
\sqrt{3} \gamma_{R} V_{i} /\left(e \cdot l \cdot f_{y}\right)<t<(2 \omega / \pi) \cdot \sqrt{\left\{\left[3 \tau_{y}\left(1-v^{2}\right)\right] /\left(K_{l} E\right)\right\}}
$$

Therefore, the thickness of the corrugated steel plate is listed in Table 1. According to the Table 1, the thickness of the model single-layer corrugated steel plate is $1 \mathrm{~mm}$.

Table 1 Calculation of Corrugated Plate Thickness in Each floor

\begin{tabular}{ccccccc}
\hline Floor & $\mathrm{V}_{\mathrm{i}}[\mathrm{KN}]$ & $\begin{array}{c}\mathrm{f}_{\mathrm{y}} \\
{\left[\mathrm{N} / \mathrm{mm}^{2}\right]}\end{array}$ & $\begin{array}{l}\tau_{\mathrm{y}} \\
{\left[\mathrm{N} / \mathrm{mm}^{2}\right]}\end{array}$ & $\begin{array}{l}\text { Minimum } \\
\text { Thickness }[\mathrm{mm}]\end{array}$ & $\begin{array}{l}\text { Total } \\
\text { Thickness }[\mathrm{mm}]\end{array}$ & $\begin{array}{l}\text { Maximum } \\
\text { Thickness [mm] }\end{array}$ \\
\hline 1 & 1507.9 & 470 & 271 & 0.43 & 0.86 & 1.18 \\
2 & 1435.2 & 470 & 271 & 0.41 & 0.82 & 1.18 \\
3 & 1290.2 & 470 & 271 & 0.37 & 0.74 & 1.18 \\
4 & 1075.1 & 470 & 271 & 0.31 & 0.62 & 1.18 \\
5 & 789.1 & 470 & 271 & 0.225 & 0.45 & 1.18 \\
6 & 433.4 & 470 & 271 & 0.125 & 0.25 & 1.18 \\
\hline
\end{tabular}

\section{Components Connection}

In order to facilitate construction and decrease the damage to components, welding connections are used in the design. The edges of the corrugated steel plate are welded to one flange of equal-leg angle steels, and the other leg are welded to the flanges of the frame. Both welds are right-angled fillet welds and the E50 type electrode. According to the specification, the fillet size $h_{f}$ for fillet welds must not be less than 1.5 times of the thickness of the thicker weld. There are two kinds of right-angle fillet welds: positive fillet welds and lateral fillet welds. According to the Steel Structure Design Code ${ }^{\text {[11] }}$ (GB50017-2017), weld strength is checked as follow:

Normal stress of positive fillet welds: $\sigma_{f}=N /\left(h_{e} l_{w}\right) \leq \beta_{f} f_{f}{ }_{f}$

Shear stress of side fillet weld: $\tau_{f}=N /\left(h_{e} l_{w}\right) \leq f^{w} f$ 
Where,

$h_{e} ; l_{w}$--- the thickness and length of the fillet weld;

$f^{w} f^{--}$the strength of the fillet weld;

$\beta_{f}$---the design increase coefficient of the positive fillet weld strength

$N$--- the shear force applied to the horizontal weld.

\section{Conclusions}

A design method of CSSWs is produced based on the shear strength of steel members. In which, the layout orientation of the corrugated steel plate, waveform selection, plate thickness, joints and connections strength are considered.

A simplified formula for the thickness of corrugated steel plates is proposed, which is controlled by bearing area ratio and the maximum of the horizontal and oblique wavelength.

The bearing capacity and shear strength of CSSW model produced meet the current codes. The model has a good seismic performance, which proved that the design scheme was reasonable.

\section{Acknowledgements}

The work was sponsored by Key Research and Development Program of Shandong Province (2015GSF122003; 2016GSF122012). The writers gratefully acknowledge the support provided and a Project of Shandong Province Higher Educational Science and Technology Program(J17KB048; J18KA208).

\section{References}

[1] M.M. Alinia, R.S. Shirazi. On the design of stiffeners in steel plate shear walls. Journal of Constructional Steel Research. Vol.65(2009), p.2069-2077.

[2] S. Shafaei, A. Ayazi, F. Farahbod.The effect of concrete panel thickness upon composite steel plate shear walls. Journal of Constructional Steel Research. Vol.117(2016), p. 81-90.

[3] C.L. Chan, Y.A. Khalid, B.B. Sahari, et al. Finite element analysis of corrugated web beams under bending. Journal of Constructional Steel Research. Vol.58(2002), p. 1391 -1406

[4] Feng Li, Liang Zhao. Elastic Bucking Analysis of Transverse Honeycomb Shaped Section Steel Plate Shear Wall. Steel Construction. Vol.29(2014), p. 59-62.

[5] Ying Liu. Nonlinear Finite Element Analysis of Semi-rigid Composite Steel Frame with Profiling Steel Plate Infill Wall. China Steel construction Society Lodge of Structural stability and Fatigue. 2012.

[6] J.W. Berman, M. Bruneau. Experimental Investigation of Light-Gauge Steel Plate Shear Walls. Journal of Structural Engineering. Vol.131(2005), p. 259-267.

[7] Wei Zhu, Hongxian Mei. Analysis of Lateral Force Performance of Corrugated Steel Plate Shear Wall. Development orientation of building materials. Vol.5(2013), p. 20-22.

[8] Guoqiang Li, Zhe Zhang, Feifei Sun. Shear Strength of H-beam with Corrugated Webs. Journal of Tongji University(Natural Science). Vol. 37 (2009), p. 709-714.

[9] China Association for Standardization of Engineering Construction. Technical specification for steel structure with corrugated webs. China Planning Press. 2011.

[10] Yanlin Guo, Qinglin Zhang, Xiao'an Wang. A Theoretical and Experimental Study of the Shear Strength of H-Shaped Members with Sinusoidal Corrugated Webs. China Civil Engineering Journal.Vol.10(2010), p. 45-52. 
[11]Ministry of Construction of the PRC. Code for Design of Steel Structure. China Planning Press. 2003. 